Uniwersytet Warmińsko-Mazurski w Olsztynie

Katedra Metod Ilościowych

Anna Rutkowska-Ziarko

\title{
WYKORZYSTANIE DOLNOSTRONNYCH WSPÓŁCZYNNIKÓW BETA W ANALIZIE RYZYKA SYSTEMATYCZNEGO NA GPW W WARSZAWIE W WARUNKACH ZMIENNEJ KONIUNKTURY GIEŁDOWEJ
}

Z a rys treści. Głównym celem badań było sprawdzenie, czy ryzyko dolnostronne jest wyceniane na GPW w Warszawie. Celem dodatkowym było przeanalizowanie kształtowania się parametrów w modelach wyceny aktywów kapitałowych w różnych fazach koniunktury giełdowej. Badania wykazały, że semiwariancja wywiera wyraźniejszy wpływ na wycenę aktywów kapitałowych w porównaniu z wariancją. Zastosowanie rozszerzonej wersji modelu CAPM pokazało, że najlepiej można modelować zyskowność akcji, uwzględniając jednocześnie klasyczne i dolnostronne współczynniki beta.

S ł o w a klu c z o w e : model CAPM, semiwariancja, ryzyko dolnostronne, dolnostronne współczynniki beta.

\section{WSTĘP}

Zaproponowana przez Markowitza (1952) koncepcja portfela efektywnego zapoczątkowała analizowanie inwestycji finansowych ze względu na zyskowność oraz mierzalne ryzyko. Teoria portfelowa była rozwijana i doskonalona, czego wynikiem było sformułowanie modelu wyceny aktywów kapitałowych niezależnie przez: Sharpe’a (1964), Lintnera (1965) i Mossina (1966).

Model ten zakłada, że przy efektywności portfela rynkowego pomiędzy ryzykiem systematycznym a zyskownością akcji istnieje związek liniowy, a jedynym czynnikiem wpływającym na wspólne zmiany cen akcji są zmiany wartości 
portfela rynkowego. W klasycznym modelu CAPM ryzyko całkowite jest wyrażone wariancją stóp zwrotu. Badania nad modelem wyceny aktywów kapitałowych można podzielić na dwa główne nurty. Pierwszy dotyczył uwzględnienia innych niż wariancja miar ryzyka, Hogan i Warren (1974) zaproponowali model wyceny aktywów kapitałowych w oparciu o semiwariancję. Drugi nurt dotyczył uwzględnienia dodatkowych, poza zmianami cen portfela rynkowego, źródeł ryzyka systematycznego. Idea ta została zrealizowana w teorii arbitrażu cenowego sformułowanej przez Rossa (1976).

Głównym celem badań było sprawdzenie, czy dolnostronne ryzyko jest wyceniane na GPW w Warszawie. Celem dodatkowym było przeanalizowanie kształtowania się parametrów w modelach wyceny aktywów kapitałowych w różnych fazach koniunktury giełdowej.

\section{METODOLOGIA}

\subsection{DOLNOSTRONNE WSPÓŁCZYNNIKI BETA}

Klasyczną miarą ryzyka w teorii finansów jest wariancja. Podstawową wadą wariancji jako miary ryzyka jest jednakowe traktowanie odchyleń ujemnych i dodatnich od średniej stopy zwrotu. W rzeczywistości odchylenia ujemne są niepożądane, a dodatnie stwarzają możliwość większego zysku. Dla mierzenia tylko odchyleń ujemnych Markowitz zaproponował semiwariancję, będącą średnią odchyleń poniżej określonego poziomu (Markowitz, 1959):

$$
d s_{i}^{2}(l)=\frac{\sum_{t=1}^{m} d_{i t}{ }^{2}(l)}{m-1},
$$

gdzie:

$d_{i t}(l)=\left\{\begin{array}{ccc}0 & \text { dla } & z_{i t} \geq l \\ z_{i t}-l & \text { dla } & z_{i t}<l\end{array}\right.$,

$z_{i t}-\quad$ stopa zwrotu w $t$ okresie $i$-tej spółki giełdowej,

$d s_{i}^{2}(l)$ - semiwariancja $i$-tej spółki giełdowej,

$m-\quad$ liczba jednostek czasowych,

l - $\quad$ równe średniej stopie zwrotu bądź stopie zwrotu zadanej przez inwestora.

Stopa zadana przez inwestora może być stopą wolną od ryzyka zmieniającą się z okresu na okres, otrzymamy wtedy następujący wzór na semiwariancję dla stopy zwrotu wolnej od ryzyka: 


$$
d s_{i}^{2}(f)=\frac{\sum_{t=1}^{m} d_{i t}{ }^{2}(f)}{m-1},
$$

gdzie:

$$
d_{i t}(f)=\left\{\begin{array}{ccc}
0 & \text { dla } & z_{i t} \geq z_{f t} \\
z_{i t}-z_{f t} & \text { dla } & z_{i t}<z_{f t}
\end{array},\right.
$$

$z_{f t}$ - stopa zwrotu wolna od ryzyka w $t$ okresie.

Semiwariancja mierzy tylko dolnostronną zmienność i uważana jest za lepszą miarę ryzyka niż wariancja (Hogan, Warren, 1972; Markowitz, 1959; Ogryczak, Ruszczyński, 1999; Sortino, Satchell, 2001). Również zgodnie z teorią perspektywy (Kahneman, Tversky, 1979) właściwsze jest stosowanie semiwariancji jako miary ryzyka zamiast wariancji (Estrada, Serra, 2005).

Rozwinięciem i uogólnieniem semiwariancji jako miary ryzyka było zdefiniowanie dolnych momentów częściowych przez Bawę (1975) i Fishburna (1977). Według tych autorów dolnym momentem cząstkowym $n$-tego stopnia dla i-tej akcji nazywamy wyrażenie:

$$
L P M_{i}^{n}=\frac{\sum_{t=1}^{m} d_{i t}{ }^{n}(l)}{m-1} .
$$

Zauważmy, że dla $n=2$ dolny moment cząstkowy jest równy semiwariancji. Stosowanie klasycznej bety $\left(\beta_{i}\right)$ związane jest z przyjęciem wariancji jako miary ryzyka. Bety dolnostronne $\left(\beta_{i}^{L P M}\right)$ natomiast wyznaczone są w oparciu o semiwariancję i inne dolne momenty cząstkowe. W literaturze wyróżniono wiele odmian bet dolnostronnych, różnicowanych ze względu na przyjętą miarę ryzyka oraz punkt odniesienia, którym może być m.in. średnia stopa wolna od ryzyka lub dowolna założona stopa zwrotu (Estrada, 2007; Kaplanski, 2004; Galagedera, Brooks, 2007). Klasyczne współczynniki beta, w przeciwieństwie do bet dolnostronnych, przyjmują jedną standardową formułę współczynników regresji w modelu Sharpe'a o postaci:

$$
z_{i t}=\alpha_{i}+\beta_{i} z_{M t}+\xi_{i t},
$$

gdzie:

$$
\beta_{i}=\frac{C O V_{i M}}{S_{M}^{2}},
$$

$z_{M t}$ - stopa zwrotu portfela rynkowego w $t$ okresie,

$C O V_{i M}$ - kowariancja stóp zwrotu i-tej akcji i portfela rynkowego,

$S_{M}^{2}$ - wariancja stóp zwrotu portfela rynkowego,

$\xi_{i t}-$ składnik losowy modelu. 
W niniejszej pracy, do określenia bet dolnostronnych, przyjęto założenie, że punktem odniesienia jest stopa wolna od ryzyka, zmieniająca swą wartość z okresu na okres (por. Price, Price, Nantell, 1982). Ponadto, posłużono się asymetrycznym mieszanym dolnym momentem cząstkowym drugiego stopnia o postaci:

gdzie:

$$
C L P M_{i}^{2}=\frac{1}{m-1} \sum_{t=1}^{m}\left(z_{i t}-z_{f t}\right) l p m_{M t},
$$

gdzie:

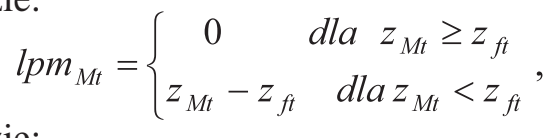

$C L P M_{i}^{2}$ - asymetryczny mieszany dolny moment czastkowy drugiego stopnia dla $i$-tej spółki giełdowej.

Biorąc pod uwagę (3) i (7), dolnostronne bety wyznaczono według wzoru (por. Price, Price, Nantell, 1982):

$$
\beta_{i}^{L P M}=\frac{C L P M_{i}^{2}}{L P M_{M}^{2}}=\frac{C L P M_{i}^{2}}{d s_{M}^{2}(f)},
$$

gdzie:

$$
\begin{gathered}
d s_{M}^{2}(f) \text { - semiwariancja portfela rynkowego wyznaczona względem stopy } \\
\text { zwrotu wolnej od ryzyka. }
\end{gathered}
$$

W omawianym podejściu, wyznaczając dolnostronne współczynniki beta, pomija się okresy, w których rynkowa stopa zwrotu jest wyższa od stopy zwrotu wolnej od ryzyka.

\subsection{RYZYKO DOLNOSTRONNE W MODELU CAPM}

W klasycznym modelu CAPM zakłada się, że przy efektywności portfela rynkowego pomiędzy ryzykiem systematycznym a zyskownością akcji istnieje związek liniowy, co opisuje następujące równanie:

$$
\bar{z}_{i}=z_{f}+\lambda_{1} \beta_{i}+\eta_{i}
$$

gdzie:

$\bar{z}_{i}-$ średnia stopa zwrotu $i$-tego waloru,

$\bar{z}_{M}$ - średnia stopa zwrotu portfela rynkowego,

$z_{f}$ - stopa zwrotu wolna od ryzyka,

$\lambda_{1}=\bar{z}_{M}-z_{f}$ - premia za ryzyko systematyczne,

$\beta_{i}$ - współczynnik beta $i$-tej akcji,

$\eta_{i}$ - składnik losowy. 
W modelu tym przyjmuje się, że inwestorzy podejmują decyzje, opierając się na oczekiwanej stopie zwrotu i ryzyku mierzonym wariancją. W praktyce oczekiwana stopa zwrotu zastępowana jest średnią stopa zwrotu. Jest ona podobnie jak wariancja i współczynniki beta szacowana na podstawie danych historycznych.

Przyjmuje się, że wariancję można stosować, gdy rozkłady stóp zwrotu są normalne, a przynajmniej symetryczne (Estrada, Serra, 2005; Galagedera, Brooks, 2007; Nantell, Price, 1979), lub funkcje użyteczności inwestorów są funkcjami kwadratowymi (Elton, Gruber, 1998; Haugen, 1996). Przy zastosowaniu semiwariancji i innych dolnostronnych miar ryzyka nie przyjmuje się żadnych założeń odnośnie do rozkładów stóp zwrotu i funkcji użyteczności (Harlow, Rao, 1989).

Kwadratowa funkcja użyteczności ma pewne niepożądane własności, przez co źle opisuje faktyczne zachowania inwestorów (Haugen, 1996). Przede wszystkim dla pewnej stopy zwrotu osiaga maksimum i jej wartość następnie maleje wraz ze wzrostem stopy zwrotu, co jest w jawnej sprzeczności z preferencjami inwestorów, którzy zawsze wolą posiadać więcej niż mniej.

Badania na rynkach kapitałowych wskazują, że rozkłady stóp zwrotu niektórych spółek giełdowych nie są rozkładami normalnymi lub przynajmniej symetrycznymi (Adcock, Shutes, 2005; Estrada, Serra, 2005; Jajuga, 2000; Kolupa, Plebaniak, 2000; Kowalewski, Kuziak, 1998; Markowski, 2001; Post, van Viet, 2006; Rutkowska-Ziarko, 2007; Sun, Yan, 2003). Nie można więc stosować wariancji, zakładając normalność stóp zwrotu.

Dodatkowo można wykazać, że również przy normalności rozkładów stóp zwrotu semiwariancja jest właściwszą miarą ryzyka niż wariancja (Rutkowska-Ziarko, 2007).

W 1974 roku Hogan i Warren przedstawili model wyceny aktywów kapitałowych dla ryzyka mierzonego semiwariancją. Za punkt odniesienia przy wyznaczaniu semiwariancji przyjęli oni stopę zwrotu zadaną przez inwestora.

Obecnie istnieje wiele metod uwzględniania ryzyka dolnostronnego w modelu wyceny aktywów kapitałowych, najprostsza z nich polega na zastąpieniu klasycznych bet betami dolnostronnymi (Estrada, 2002):

$$
\bar{z}_{i}=z_{f}+\lambda_{1} \beta_{i}^{L P M}+\eta_{i} .
$$

W celu odróżnienia modelu dla ryzyka dolnostronnego od klasycznego modelu wyceny aktywów kapitałowych jest on nazywany modelem D-CAPM.

Można także stosować model CAPM, w którym jednocześnie wyceniane jest ryzyko dwustronne i jednostronne; w pracy zostaną wykorzystane dwa warianty takiego modelu. W pierwszym wariancie za miarę ryzyka systematycznego zostanie przyjęta różnica pomiędzy betą klasyczną a betą dolnostronną:

$$
\bar{z}_{i}=z_{f}+\lambda_{1}\left(\beta_{i}-\beta_{i}^{L P M}\right)+\eta_{i} .
$$


Model ten będzie nazywany w dalszej części pracy jako zmodyfikowany model wyceny aktywów kapitałowych (Z-CAPM).

Badania przeprowadzone na Giełdzie Papierów Wartościowych w Warszawie wskazały na występowanie silnego związku liniowego pomiędzy zyskownością stóp zwrotu akcji a różnicą bet (Rutkowska-Ziarko, Markowski, 2009).

W drugim wariancie w modelu będą jednocześnie występowały bety klasyczne i dolnostronne, będzie on określany jako rozszerzony model wyceny aktywów kapitałowych (R-CAPM):

$$
\bar{z}_{i}=z_{f}+\lambda_{1} \beta_{i}+\lambda_{2} \beta_{i}^{L P M}+\eta_{i},
$$

gdzie:

$\lambda_{2}$ - premia za ryzyko dolnostronne.

Jest to model podobny do zaproponowanego przez Kima i Zumwalta (1979). W modelu Kima i Zumwalta występują dwa rodzaje bet, jedne wyznaczone są dla okresów, w których występuje dobra koniunktura, drugie przy złej koniunkturze. Za występowanie złej koniunktury przyjmuje się sytuację, gdy stopa zwrotu z portfela rynkowego jest niższa od pewnego punktu odniesienia. Za ten punkt przyjmuje się alternatywnie średnią stopę zwrotu portfela rynkowego, stopę wolną od ryzyka lub zerową stopę zwrotu (Kim, Zumwalt, 1979).

W modelu Kima i Zumwalta nie występuje jednak ryzyko dolnostronne, w tym sensie, że za miarę ryzyka całkowitego przyjmowana jest wariancja.

\section{WYNIKI EMPIRYCZNE}

Badaniami objęto spółki notowane na Giełdzie Papierów Wartościowych w Warszawie wchodzące w skład indeksów: WIG20, WIG40 i WIG80. Badania dotyczyły miesięcznych stóp zwrotu w latach 2000-2008. Przeanalizowano łącznie 59 spółek giełdowych notowanych nieprzerwanie w całym okresie badawczym. Okres badawczy podzielono na 5 podokresów, ze względu na zmiany koniunktury giełdowej okresy te były podobnej długości, od 21 do 23 miesięcy.

Wyróżniono: niewielki trend spadkowy, trend horyzontalny, niewielki trend wzrostowy, silny trend wzrostowy oraz silny trend spadkowy. W każdym okresie wyznaczono średnią miesięczną stopę zwrotu z indeksu WIG oraz średnią stopę wolną od ryzyka. 
Tabela 1. Podokresy badawcze

\begin{tabular}{ccccc}
\hline $\begin{array}{c}\text { Numer } \\
\text { okresu }\end{array}$ & Koniunktura & $\begin{array}{c}\text { Długość } \\
\text { w miesiącach }\end{array}$ & $\begin{array}{c}\text { Średnia stopa zwrotu } \\
\text { indeksu WIG }\end{array}$ & $\begin{array}{c}\text { Stopa zwrotu wolna } \\
\text { od ryzyka }\end{array}$ \\
\hline I & niewielki trend spadkowy & 21 & $-1,78$ & 1,29 \\
II & trend horyzontalny & 21 & 1,63 & 0,63 \\
III & niewielki trend wzrostowy & 22 & 2,40 & 0,5 \\
IV & silny trend wzrostowy & 21 & 3,77 & 0,35 \\
V & silny trend spadkowy & 23 & $-2,67$ & 0,45 \\
\hline
\end{tabular}

Źródło: obliczenia własne.

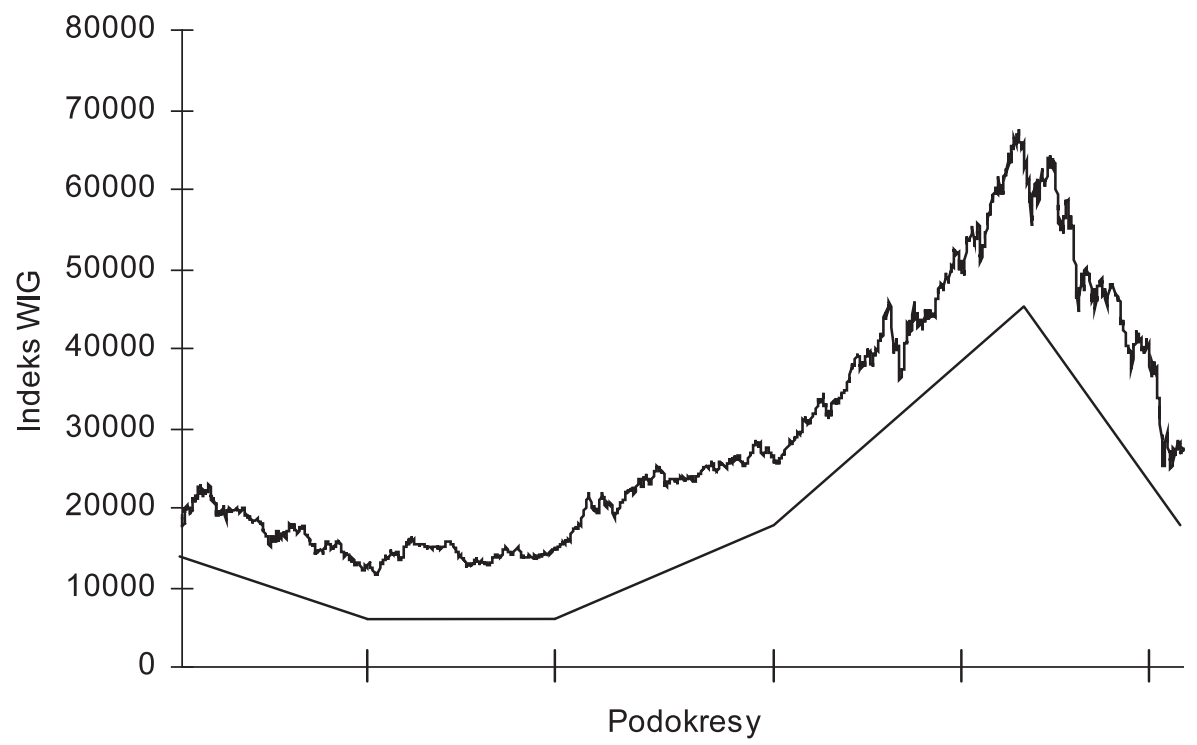

Wykres 1. Wartości indeksu WIG w latach 2000-2008

Źródło: opracowanie własne.

Następnie oszacowano średnie stopy zwrotu oraz klasyczne i dolnostronne współczynniki beta w poszczególnych okresach. Stosując regresję przekrojową, oszacowano parametry modeli: CAPM, D-CAPM, Z-CAPM i R-CAPM. Dopasowanie modeli do danych empirycznych zbadano za pomocą skorygowanego stopniami swobody współczynnika determinacji $\left(\bar{R}^{2}\right)$. 
Tabela 2. Oszacowania parametrów modelu CAPM w poszczególnych okresach

\begin{tabular}{crrrrc}
\hline Okres & $\hat{\lambda}_{0}$ & $t_{\lambda_{0}}$ & $\hat{\lambda}_{1}$ & $t_{\lambda_{1}}$ & $\bar{R}^{2}$ \\
\hline I & $-1,939$ & $-3,71[0,001]$ & 0,336 & $0,65[0,521]$ & 0,000 \\
II & 2,047 & $3,40[0,001]$ & $-1,197$ & $-2,03[0,047]$ & 0,051 \\
III & 0,779 & $0,91[0,366]$ & 2,882 & $4,59[0,000]$ & 0,257 \\
IV & 2,835 & $3,49[0,001]$ & 3,299 & $4,70[0,000]$ & 0,267 \\
V & $-1,907$ & $-2,81[0,007]$ & $-1,424$ & $-2,53[0,014]$ & 0,085 \\
Całość & 0,748 & $1,48[0,143]$ & 0,409 & $0,851[0,398]$ & 0,005 \\
\hline
\end{tabular}

W nawiasach kwadratowych podano prawdopodobieństwo przekroczenia wartości empirycznej statystyki $t$-Studenta.

Źródło: obliczenia własne.

Premie za ryzyko okazały się istotne $(\alpha=0,05)$ we wszystkich podokresach z wyjątkiem I. Jednak biorąc pod uwagę cały okres, premia ta była statystycznie nieistotna. W okresach wzrostowych premia za ryzyko była dodatnia. Klasyczny model CAPM w niewielkim stopniu opisuje zależność pomiędzy średnią zyskownością akcji a ryzykiem systematycznym, na co wskazują niskie wartości współczynników determinacji. Przy czym zmienność rentowności najlepiej wyjaśniana była w okresach hossy. W okresach hossy wyniki oszacowań modelu są zgodne z postulatami klasycznego modelu wyceny aktywów kapitałowych.

Tabela 3. Oszacowania parametrów modelu D-CAPM w poszczególnych okresach

\begin{tabular}{cccccc}
\hline Okres & $\hat{\lambda}_{0}$ & $t_{\lambda_{0}}$ & $\hat{\lambda}_{1}$ & \multicolumn{1}{c}{$t_{\lambda_{1}}$} & $\bar{R}^{2}$ \\
\hline I & 1,356 & $2,43[0,018]$ & $-3,665$ & $-6,477[0,000]$ & 0,414 \\
II & 2,760 & $6,81[0,000]$ & $-1,695$ & $-6,550[0,000]$ & 0,419 \\
III & 5,590 & $6,77[0,000]$ & $-1,772$ & $-2,27[0,026]$ & 0,067 \\
IV & 6,600 & $10,17[0,000]$ & $-0,994$ & $-1,596[0,116]$ & 0,026 \\
V & $-0,211$ & $-0,345[0,731]$ & $-3,050$ & $-5,768[0,000]$ & 0,357 \\
Całość & 2,275 & $4,93[0,000]$ & $-1,180$ & $-2,54[0,014]$ & 0,086 \\
\hline
\end{tabular}

Źródło: obliczenia własne.

W modelu D-CAPM we wszystkich okresach otrzymano ujemną premię za ryzyko, jest ona istotna ( $\alpha=0,05)$ za wyjątkiem okresu silnego wzrostu. Oznacza to, że inwestorzy nie musieli ponosić dodatkowego ryzyka w ujęciu dolnostronnym, by osiągnać wyższe stopy zwrotu, co nie jest zgodne z klasyczną teorią wyceny aktywów kapitałowych. W okresie hossy model D-CAPM w niewielkim 
stopniu wyjaśnia zmienność stóp zwrotu. W pozostałych okresach współczynniki determinacji są wyższe niż dla klasycznego modelu CAPM.

Tabela 4. Oszacowania parametrów modelu Z-CAPM w poszczególnych okresach

\begin{tabular}{crrrrc}
\hline Okres & \multicolumn{1}{c}{$\hat{\lambda}_{0}$} & \multicolumn{1}{c}{$t_{\lambda_{0}}$} & $\hat{\lambda}_{1}$ & $t_{\lambda_{1}}$ & $\bar{R}^{2}$ \\
\hline I & $-1,094$ & $-3,86[0,000]$ & 3,754 & $7,79[0,000]$ & 0,507 \\
II & 1,806 & $6,81[0,000]$ & 3,236 & $10,01[0,000]$ & 0,631 \\
III & 2,529 & $7,75[0,000]$ & 4,922 & $11,33[0,000]$ & 0,687 \\
IV & 4,885 & $11,57[0,000]$ & 3,566 & $6,91[0,000]$ & 0,446 \\
V & $-3,617$ & $-13,83[0,000]$ & 4,555 & $4,10[0,000]$ & 0,214 \\
Całość & 0,916 & $8,37[0,000]$ & 4,284 & $7,55[0,000]$ & 0,491 \\
\hline
\end{tabular}

Źródło: obliczenia własne.

W modelu Z-CAPM, w którym ryzyko określone jest różnicą bet $\left(\beta_{i}-\beta_{i}^{L P M}\right)$, premie za ryzyko są dodatnie i istotne $(\alpha=0,001)$. Natomiast w okresach spadkowych występuje istotna, ujemna stopa wolna od ryzyka. Model ten w dużym stopniu wyjaśnia zmienność stóp zwrotu za wyjątkiem okresu silnej bessy na rynku kapitałowym.

Przy szacowaniu modelu R-CAPM wystąił problem korelacji zmiennych objaśniających ze sobą. Pomiędzy betami klasycznymi i dolnostronnymi we wszystkich badanych okresach występuje istotna korelacja, co przedstawia tabela 5 .

Tabela 5. Współczynniki korelacji liniowej Persona pomiędzy betami klasycznymi i dolnostronnymi w poszczególnych okresach

\begin{tabular}{ccccccc}
\hline Okres & I & II & III & IV & V & Całość \\
\hline Współczynnik korelacji & 0,816 & 0,659 & 0,809 & 0,518 & 0,497 & 0,883 \\
\hline
\end{tabular}

Źródło: obliczenia własne.

Powoduje to, że w modelu R-CAPM występowałyby zmienne silnie skorelowane. Chcąc wyeliminować ten problem, zostaną wyznaczone reszty z modeli liniowych opisujących wpływ dolnostronnych bet na bety klasyczne:

$$
\beta_{i}=\alpha_{0}+\alpha_{1} \beta_{i}^{L P M}+\varepsilon_{i} \text {. }
$$

Następnie reszty zastąpią bety klasyczne w modelu R-CAPM. Reszty te będą reprezentowały ryzyko systematyczne dwustronne po wyeliminowaniu wpływu ryzyka systematycznego dolnostronnego. 
W rozszerzonej wersji modelu CAPM premia za ryzyko rozbita jest na dwie części: premia za ryzyko dwustronne i premia za ryzyko dolnostronne. We wszystkich okresach premia za ryzyko dwustronne jest dodatnia, a premia za ryzyko dolnostronne ujemna. W okresach hossy część premii odpowiadającej ryzyku dwustronnemu jest wyższa co do wartości bezwzględnej od premii odpowiadającej ryzyku dolnostronnemu. Model R-CAPM w dużym stopniu wyjaśnia zmienność zyskowności akcji we wszystkich badanych okresach.

Tabela 6. Oszacowania parametrów modelu R-CAPM w poszczególnych okresach

\begin{tabular}{crrrrrrc}
\hline Okres & $\hat{\lambda}_{0}$ & \multicolumn{1}{c}{$t_{\lambda_{0}}$} & $\hat{\lambda}_{1}$ & \multicolumn{1}{c}{$t_{\lambda_{1}}$} & \multicolumn{1}{c}{$\hat{\lambda}_{2}$} & $t_{\lambda_{2}}$ & $R^{2}$ \\
\hline I & 1,356 & $5,54[0,000]$ & 3,579 & $15,52[0,000]$ & $-3,665$ & $-14,78[0,000]$ & 0,887 \\
II & 2,760 & $8,50[0,000]$ & 3,593 & $5,72[0,000]$ & $-1,695$ & $-8,17[0,000]$ & 0,627 \\
III & 5,590 & $11,65[0,000]$ & 5,075 & $10,62[0,000]$ & $-1,772$ & $-3,914[0,000]$ & 0,685 \\
IV & 6,660 & $15,09[0,000]$ & 5,238 & $8,33[0,000]$ & $-0,994$ & $-2,37[0,021]$ & 0,557 \\
V & $-0,211$ & $-0,42[0,674]$ & 4,446 & $5,41[0,000]$ & $-3,05$ & $-7,05[000]$ & 0,570 \\
Całość & 2,275 & $6,65[0,000]$ & 4,064 & $6,91[0,000]$ & $-1,180$ & $-3,42[0,000]$ & 0,498 \\
\hline
\end{tabular}

Źródło: obliczenia własne.

Można zauważyć, że parametry wszystkich omawianych modeli zmieniają się wraz ze zmianą sytuacji na rynku kapitałowym. Najwyraźniej zmiany zauważane są pomiędzy parametrami modeli z IV i V okresu. W modelach CAPM, D-CAPM i R-CAPM najbardziej zbliżone są parametry w okresach III i IV. W modelu Z-CAPM wartości parametrów strukturalnych są podobne w okresach: II, III i IV.

\section{PODSUMOWANIE}

Badania wykazały, że semiwariancja wywiera wyraźniejszy wpływ na wycenę aktywów kapitałowych w porównaniu z wariancją. Zastosowanie rozszerzonej wersji modelu CAPM pokazało, że najlepiej można modelować zyskowność akcji, uwzględniając jednocześnie obydwie odmiany współczynników beta. Oszacowania stopy wolnej od ryzyka i premii za ryzyko są różne w poszczególnych modelach.

Parametry wszystkich omawianych modeli zmieniają się wraz ze zmianą sytuacji na rynku kapitałowym. Największe zmiany można było zaobserwować po wystąpieniu załamania na rynkach finansowych. 


\section{LITERATURA}

Adcock C. J., Shutes K. (2005), An analysis of skewness and skewness persistence in three emerging markets, „Emerging Markets Review”, 6, 396-418.

Bawa V. (1975), Optimal rules for ordering uncertain prospects, „Journal of Financial Economics”, 2(1), 95-121.

Elton E. J., Gruber M. J. (1998), Nowoczesna teoria portfelowa i analiza papierów wartościowych, Wig Press, Warszawa.

Estrada J. (2002), Systematic risk in emerging markets: the D-CAPM, „Emerging Markets Review”, 3, 365-379.

Estrada J. (2007), Mean-semivariance behavior: Downside risk and capital asset pricing, „International Review of Economics \& Finance”, 16, 169-185.

Estrada J., Serra A. (2005), Risk and return in emerging markets: family matters, „Journal of Multinational Financial Management”, 15, 257-272.

Fishburn P. (1977), Mean-risk analysis with risk associated with below-target returns, „The American Economic Review”, March, 116-126.

Galagedera U. A., Brooks R. D. (2007), Is co-skewness a better measure of risk in the downside than downside beta? Evidence in emerging market data, „Journal of Multinational Financial Management”, 17, 214-230.

Harlow W. V., Rao R. K. S. (1989), Asset pricing in a generalized mean-lower partial moment framework: theory and evidence, „Journal of Financial and Quantitative Analysis”, 24, 285-311.

Haugen A. (1996), Teoria nowoczesnego inwestowania, WIG-Press, Warszawa.

Hogan W., Warren J. (1972), Computation of the efficient boundary in the E-S portfolio selection model, „Journal of Finance and Quantitative Analysis”, September.

Hogan W., Warren J. (1974), Toward the development of an equilibrium capital-market based on semivariance, „Journal of Finance and Quantitative Analysis”, January.

Jajuga K. (red.) (2000), Metody ekonometryczne i statystyczne w analizie rynku kapitałowego, Wydawnictwo Naukowe AE we Wrocławiu, Wrocław.

Kahneman D., Tversky A. (1979), Prospect theory: An analysis of decision under risk, „Econometrica”, 47, 263-291.

Kaplanski G. (2004), Traditional beta, downside beta and market risk premiums, „Quarterly Review of Economics and Finance”, 44, 636-653.

Kim M. K., Zumwalt J. K. (1979), An analysis of risk in bull and bear markets, „Journal of Finance and Quantitative Analysis”, December, 1015-1025.

Kolupa M., Plebaniak J. (2000), Budowa portfela lokat, PWE, Warszawa.

Kowalewski G., Kuziak K. (1998), Statystyczne miary ryzyka dla polskiego rynku akcji, „Finanse i Bankowość”, 4, Wydawnictwo Naukowe AE we Wrocławiu, Wrocław.

Lintner J. (1965), The Valuation of Risk Assets and the Selection of Risky Investments in Stock Portfolio and Capital Budgets, „Review of Economics and Statistics”, t. 47, 13-37.

Markowitz H. (1952), Portfolio selection, „Journal of Finance”, 7, 77-91.

Markowitz H. (1959), Portfolio selection: efficient diversification of investments, John Wiley and Sons, New York. 
Markowski L. (2001), Risk analysis of capital investment on the Warsaw Stock Exchange in the context of portfolio theory, „Economic Science”, 3, Wydawnictwo UWM, 159-177.

Mossin J. (1966), Equilibribium in a Capital Asset Market, „Econometrica”, 768-783.

Nantell T. J., Price B. (1979), An analytical comparision of variance and semivariance capital market theories, „Journal of Finance and Quantitative Analysis”, XIV, No. 2, 221-242.

Ogryczak W., Ruszczyński A. (1999), From stochastic dominance to mean-risk models: semideviations as risk measures, „European Journal of Operational Research”, 116, 33-35.

Post T., van Viet P. (2006), Downside risk and asset pricing, „Journal of Banking and Finance”, 30, 823-849.

Price K., Price B., Nantell T. J. (1982), Variance and lower partial moment measures of systematic risk: some analytical and empirical results, „Journal of Finance”, XXXVII, No. 3, 843-855.

Ross S. A. (1976), The arbitrage theory of capital asset pricing, „Journal of Economic Theory”, No. 3.

Rutkowska-Ziarko A. (2007), Wykorzystanie wariancji i semiwariancji do budowy portfela akcji przy normalności rozkładów stóp zwrotu, „Przegląd Statystyczny”, 4, 105-116.

Rutkowska-Ziarko A., Markowski L. (2009), Wykorzystanie dolnostronnych współczynników beta do oceny ryzyka na przykładzie spółek notowanych na GPW w Warszawie, „Prace Naukowe AE we Wrocławiu”: Inwestycje finansowe i ubezpieczenia - tendencje światowe a polski rynek, Wrocław, s. 411-418.

Sortino F., Satchell S. (2001), Managing downside risk in fi nanaial markets: theory, practice and implementation, Butterwarth-Heinemann, Oxford.

Sun Q., Yan Y. (2003), Skewness persistence with optimal portfolio selection, „Journal of Banking and Finance”, 27, 1111-1121.

Sharpe W. F. (1964), Capital Asset Prices: A Theory of Market Equilibrium Under Conditions of Risk, „Journal of Finance”, 425-442.

\section{APPLICATION OF DOWNSIDE BETA TO SYSTEMATIC RISK ASSESSMENT ON THE WARSAW STOCK EXCHANGE DURING CHANGEABLE TREND CYCLES}

A b s tr a c t . The immediate objective of the study was to analyze whether the downside risk is priced at the Warsaw Stock Exchange. The intermediate objective was to analyze changes in the parameters in the capital asset pricing models at different trend cycles of the stock exchange market. It was found that semi-variance had a more noticeable effect on the capital asset pricing than the variance. The application of the CAPM extended model proved that the profitability of the stocks can be best modeled by using the combination of both the classic and the downside beta.

K e y w o r d s : capital asset pricing model, semi-variance, downside risk, downside beta. 